\title{
Mapping Governance Transfer by 12 Regional Organizations: A Global Script in Regional Colors
}

\author{
Tanja A. Börzel and Sören Stapel
}

\section{Introduction}

Studies on governance transfer by regional organizations (ROs) are on the rise. The extant literature has mainly focused on democracy and human rights (for an overview see Pevehouse forthcoming; McMahon and Baker 2006). Meanwhile, the promotion of other governance standards, such as the rule of law and the fight against corruption, have received far less attention (but see Jakobi 2013a; Zürn et al. 2012) and a systematic comparison of the general patterns of governance transfer by ROs across time, space, and issue areas is still missing.

This chapter is the first step of a systematic empirical analysis of the efforts of ROs to prescribe, promote, and protect standards for legitimate governance institutions in their member states. It seeks to place the case studies presented by the other contributions to this volume in a broader context of what we see as a global trend towards increased governance transfer by ROs. These global trend(s), however, are not driven by the diffusion of a single global script. Beyond their general prescription, the development of the precision and scope of governance standards and the instruments to promote them is a decentralized process in which the various ROs amend and modify the script. These changes are subsequently adopted, adapted, rejected, or ignored by others, which may explain why we see both increasing similarities as well as differences of standards and instruments.

In order to develop our argument, the first part of the chapter elaborates on the analytical framework of this edited volume (Börzel and van Hüllen forthcoming). While the case study chapters analyze the empirical phenomenon of interest and possible factors to explain its emergence and evolution, we are concerned with the operationalization and measurement of the dependent variable, that is, governance transfer by ROs. By further specifying the two main 
important components of the governance transfer concept - standards and mechanisms - we are able to make the concept accessible to empirical investigation. The focus on these two components also allows us to develop an analytical framework for mapping the emergence and evolution of governance transfer. The framework distinguishes between (1) the general prescription of a governance standard at the regional level, (2) its increasing precision into main dimensions (for example political, socio-economic, and cultural human rights), and (3) specific norms (for example the prohibition of torture), with regard to the quantity of main dimensions and specific norms covered, and the prescription, precision, and scope of the instruments designed for its promotion and protection.

Based on this analytical framework, the second part of the chapter maps the emergence and evolution of governance transfer over time, across regions and ROs, and across standards. This mapping allows us to draw conclusions about our two main research questions. First, how has governance transfer by ROs evolved over time? Do we find incremental processes of evolution or are there specific periods of change? Second, is there systematic variation over time, across regions and governance standards? Do their approaches to promoting governance standards converge?

We begin by providing a general overview of the evolution of governance transfer since the founding of these ROs in the post-World War II and post-Cold War era, pointing out major similarities and differences. We find that the efforts to prescribe, promote, and protect standards at the regional level have increased, especially since around the turn of the millennium. By the year 2012, almost all of the 12 ROs in our data set were prescribing, promoting, and protecting standards for legitimate governance institutions with regard to democracy, human rights, rule of law, and the fight against corruption. ${ }^{1}$ However, these processes are not uniform, and the efforts of ROs vary in their precision and scope. In a second step, we look more closely at the content of standards and the instruments to promote them. Our analysis reveals that ROs are prescribing increasingly precise governance standards, broadening their scope, and developing a set of harder instruments with regard to some governance standards. At the same time, regional differences persist, particularly with regard to the scope of both governance standards and instruments for their promotion. 
The chapter concludes that we do see a global trend towards governance transfer by ROs. However, there is no central global script that is simply downloaded by ROs. Instead, by 'localizing' (Acharya 2004) globalized governance standards, ROs do not only translate them into their cultural, political, and social context; they write themselves into the global script by rewriting existing parts or adding new parts which are then adopted and localized by other ROs.

\section{The governance transfer data set}

Börzel and van Hüllen (forthcoming; see also Börzel et al. 2013: 6) conceptualize governance transfer as being based on three components: actors, standards, and mechanisms. While the actor component is fairly obvious - ROs are the providers of governance standards, and their member states are the addressees - in this chapter we focus on the mapping of the other two components (see also Börzel et al. 2011). Therefore, in the following section, we first provide an operationalization of standards and mechanisms. This operationalization is then transformed into a codebook which guides the empirical data collection based on a document analysis. We introduce the data set by presenting its design, and by providing information on the processes of data collection.

\section{Operationalizing governance transfer by regional organizations}

\section{Standards: Content}

As we are interested in the ROs' criteria for legitimate governance institutions within the political system, we find four abstract standards to be major points of reference: democracy, human rights, the rule of law, and the fight against corruption. These standards for legitimate governance institutions form part of a global script for 'good governance', which enjoys universal acceptance or what Risse, Ropp, and Sikkink have referred to as 'prescriptive status' (Risse et al. 2013).

The content of these abstract standards is, of course, highly contested and subject to countless debates and propositions. Standards are interrelated and depend on their exact 
definition, and they may overlap significantly. A substantial approach to the rule of law would include human rights, while the rule of law and human rights might be seen as essential elements of (liberal) democracy (see Landman 2013). Therefore, to keep the four standards analytically distinct, we adopt a narrow definition of each. Our categorization as laid out below might differ from the label an organization uses. For example, a RO might speak of good governance when referring to the independence of judiciary, which falls into our rule of law category. By covering a broad range of norms, rules, and procedures, this approach allows us to compare the governance transfer frameworks that ROs apply.

For democracy, we distinguish between three main dimensions. First, representation, accountability, and transparency describe the delegation of the execution of political authority, and possible routes for control of the executive by the people (Przeworski et al. 2000). Second, participation refers to the political involvement of the people. Here we cover elements of participatory democracy (popular initiatives, referenda, recall elections), the involvement of parties and civil society actors, which can range from pressure groups and non-governmental organizations to citizens' initiatives, groups, and movements, and, finally, also the media (Verba 1967). Third, elections then form a link between representation and participation (Lijphart 1995). Rules and procedures defining standards for legitimate elections refer to electoral law, principles of suffrage, organizational structure, and control mechanisms.

Human rights are special in two ways as they are substantive norms which impose requirements for content, as well as being codified in international law. Regarding the content of human rights, three different generations or main dimensions can be distinguished and specific human rights norms, rules, and procedures can be best grouped according to the different types or generations of human rights (Simmons 2009; Forsythe 2012). These are civil and political rights; economic and social rights; cultural and collective rights. Finally, gender equality, often framed as women's rights, and anti-discrimination rights are cross-cutting issues. These are not confined to one group of human rights but can be linked to any of them, for example when asserting the right to work specifically for women.

Meanwhile, two different conceptions of the rule of law can be distinguished (Brooks 2003; Zürn et al. 2012), which we further develop into four main dimensions of the rule of law 
standards. First, a 'formal' perspective defines procedural requirements of the legal framework, which we cover under two dimensions: supremacy of law and principles of state organization. Supremacy of law is measured by looking at prescribed standards such as the accountability of state bodies and standards prohibiting unconstitutional changes of government. Principles of state organization mean that governments and other state bodies should not have the ability to exercise unchecked power over or directly influence other state bodies. The second 'substantial' approach broadens this narrow perspective by including certain substantive rights necessary for a rule of law. It covers the entire process from the initial legislation to the adjudication of previously set standards in the nation state. These are grouped under the main dimensions of principles of law-making, law application, and law enforcement, and as promulgation and justice. Law and proceedings need to be sufficiently clear, stable, and publicly available to expect norm-consistent behavior by the people, while at the same time people should have access to and be able to afford legal advice and representation. Due process is a central clause and a point in case.

As a final standard, we include the fight against corruption as one aspect of a narrower understanding of good governance. This standard also relates to all, but does not fall exclusively under one of the other three standards. We have included four main dimensions. First, because corruption is considered a generic term for different kinds of misbehavior, it needs to be properly defined (Gardiner 2001; Philp 2001). Second, preventive measures impede corruption by setting norms and procedures to forestall the possibility of acting in corrupt ways in the first place. States can initiate regulations that decrease the likelihood that state officials might exhibit corrupt behavior (Jakobi 2013a). The third dimension, monitoring and enforcement, primarily refers to the actors involved in the process of detecting corruption. These can range from state bodies to state agencies, such as customs authorities and ombudsmen, to specialized anticorruption agencies (Rose-Ackermann 1999; de Sousa et al. 2008). Lastly, the anti-corruption norm often prescribes prosecution, possible penalties, and sanctions. Since corruption is often not restricted to the territory of a single nation state, this dimension can include norms and rules for transnational and international cooperation. The fight against corruption follows a slightly different logic because the anti-corruption norm not only prescribes and promotes standards of good behavior, but directly prescribes monitoring and enforcement mechanisms and sanction regimes in the domestic context of the member states. For democracy, human rights, and rule of 
law, we do not cover these procedural standards, with the exception of election monitoring under the election dimension of democracy.

\section{Mechanisms: Instruments}

Several types of instruments can be identified through which ROs promote and/or protect standards for legitimate governance institutions seeking to induce compliance. These may be bodies mandated with a specific task or treaty provisions regulating certain procedures. In order to illustrate what such instruments for governance transfer by ROs might look like, the remainder of this section outlines four different types of instruments: litigation and military force (coercion), sanctions and rewards (incentives), assistance (capacity-building), and fora for dialogue and exchange (persuasion and socialization) (Börzel and Risse 2009b; Börzel and Risse 2012b).

The transfer of governance institutions does not necessarily take place in a non-coercive context. ROs can rely on both legal and military coercion for the enforcement of their governance standards. Standards can be legally binding if they are inscribed in (regional) international law ratified by the member states, for example the founding treaties or a charter of the RO, or if they are set in secondary legislation by the RO that has a supranational nature. In these cases, the RO might have the mandate to monitor compliance with these standards (for example a regular reporting mechanism or body entrusted with monitoring) and, if necessary, (re-)establish compliance. Enforcement mechanisms can take the form of a supranational dispute settlement procedure or an international (regional) court that delivers legally binding rulings (Alter and Hooghe forthcoming). Besides litigation, ROs may also be authorized to use physical coercion to enforce their governance standards, drawing on regional or national military force.

Besides the legal or military enforcement of standards for legitimate governance institutions, ROs can also set incentives for the norm addressees in order to facilitate compliance. Institutional provisions for setting incentives usually take the form of codified (political) conditionality, either promising rewards (positive conditionality) or threatening sanctions (negative conditionality) based on the performance of the target, thereby establishing a direct link between certain conditions and respective incentives. Positive incentives can, for example, 
be accession to the RO, participation in programs, and eligibility for (additional) funds. The latter are not necessarily used for governance transfer as such (see below for assistance), but conditional upon the compliance with or efforts made to meet certain standards. Negative incentives are not simply the withholding of rewards if the condition is not met, but can also be sanctions that alter the status quo, for example the suspension of membership or normally unconditional aid.

While the RO can use aid as an incentive, it can also provide technical and financial assistance to directly support the creation or modification of legitimate governance institutions in member states or third countries. Capacity-building by the RO may involve the creation of (formalized) programs with a specific budget and clearly defined procedures, for example for the implementation of projects or budget support.

Finally, the RO can create fora for exchange and dialogue, bringing together different actors to facilitate compliance with standards for legitimate governance institutions through processes of persuasion and socialization. The purpose of such practices can range from an exchange of views to the transfer of knowledge and expertise. These fora may take the form of regular meetings, workshops, or seminars organized by the RO as well as formal bi- or multilateral political dialogue. They can also be linked to a best practice exercise through monitoring and benchmarking.

Sometimes, it can be difficult to draw a clear line between different types of instruments, especially when dealing with sanctions (coercion or negative incentive) or development assistance (capacity-building or positive incentive). However, what differs is their underlying logic: economic and political sanctions as negative incentives leave a (theoretical) choice to the targeted actor to either accept the costs inflicted by the RO or change his or her behavior accordingly, which is (in theory) not the case with coercive measures that force behavioral change. Finally, the more the instruments encroach on the behavior of member states, the harder they become. While assistance, dialogue, and rewards are rather soft, sanctions, litigation, and military force make non-compliance increasingly costly, if not prohibitive, for the member states. 


\section{Data collection and processing}

Based on the above-mentioned operationalization of governance transfer by ROs, we have developed a codebook for mapping the efforts of ROs in prescribing and promoting governance standards. The focus lies on content and instruments, which can be assessed separately with regard to the four abstract governance standards we have identified. The treaties and secondary law that serve as our data source and are included in the data set encompass 12 ROs with overall approximately 120 treaties and secondary legislation. We have developed a codebook that has helped us to retrieve information from the documents. Overall, we have applied 402 codes to the data sources. Only a small proportion of the codebook items are concerned with promoters, addressees, and targets (48 items) or the instruments to induce compliance (62 items). The main body of the codebook, 289 items, has served to collect data for the governance standards set by ROs. These can be further broken down: we have coded slightly fewer items for democracy and rule of law standards (51 and 58 items respectively) than for the human rights and anticorruption norms (99 and 81 items respectively). As for the instruments, we have coded persuasion and socialization (11 items), capacity-building (ten items), positive and negative incentives (25 items), and legal and military coercion (16 items). $<x e n>^{2}</ x e n>$

All items were coded in a binary way as being either present or absent in a particular document. We have covered a sufficient number of items under each individual standard. For instance, the fundamental political and civil rights dimension was composed of 27 individual items, ranging from the prohibition of torture and cruelty, and the freedoms of opinion, expression, and assembly, to the protection of children and matrimonial equality. We included mutually exclusive items only twice, and both can be found in the democracy issue area. First, we coded for different democratic systems in the participation dimension, such as parliamentary and presidential democracies. Second, in the elections dimension, codes were mutually exclusive when coding for vote restrictions (minimum and maximum age limits for voting and universal adult suffrage) and for voting systems (proportional representation, semi-proportional representation, and so on). Mutually exclusive codes created potential problems in the assessment of these dimensions of democracy. If one of the items was found in a document, it was potentially impossible for any other item to occur at the same time. Consequently, absolute and relative presentations are distorted, as both values will be significantly lower than in the 
other dimensions. However, since this problem only occurs with democracy, we have flagged out the distortion in the empirical analysis.

Based on the coding, we can make several comparisons. The distinction between standards, their dimensions or specific norms, and individual items allow us to draw comparisons between different levels of precision and scope, as we have coded these items independently of each other. Regarding the precision of governance standards, we can assess the development from very abstract standards to very specific norms. A RO may refer to very abstract human rights and to less abstract norms of fundamental civil and political rights. However, this does not mean that ROs must also further specify these abstract standards into very precise norms, for instance regarding the prohibition of torture and cruelty. On the contrary, we can aggregate the precise norms along their main dimensions, identified in the previous section on standards, and still make comparisons regarding the more abstract standards of human rights and the respective dimensions.

Regarding the scope of governance standards, we can compare their evolution, that is, when and where individual standards or norms were adopted by a particular RO. As these individual items also fall under a particular dimension of human rights, not only can we assess when the fundamental civil and political norms were prescribed for the first time; the data set also allows us to determine how much weight a $\mathrm{RO}$ attributes to a particular dimension. This is because we can examine how many of the individual items are covered in a $\mathrm{RO}$ at a specific point in time, in both absolute and relative terms.

Equally, both precision and scope can be assessed for the instruments of governance transfer. By increased precision of instruments, we mean the elaboration of abstract compliance mechanisms into more precise terms, such as technical and/or financial assistance and potentially assigned funding instead of the mere mentioning of assistance. With regard to the scope of instruments, we can assess the different types of abstract instruments that ROs can apply simultaneously or consecutively, for example dialogue and assistance. The scope of instruments also means the different components within a type of instrument: for example, political and financial sanctions, the suspension of membership rights, or membership all refer to the scope of the incentive instrument. 
The data set is original in (at least) three ways. First, the chosen time frame allows us to assess the historical development of governance transfer from its very beginning to more recent trends. We include instances of governance transfer from as early as 1945, or the year of establishment, up until the year 2012. By covering almost 65 years, this data set enables us to draw conclusions about trajectories across macro-regions and across organizations.

Second, we cover the formal codification of governance standards and instruments in a systematic and comprehensive way. Since our primary research interest lies in the formal prescription and promotion of these standards, the codification of the respective norms, rules, and instruments in official documents serves as our main data source. The downside, of course, is the lack of information on informal practices in prescribing governance standards and also the actual promotion and protection of these standards in member states. While it is impossible to include the informal aspects in this broad and temporally comprehensive data set, the case studies in this volume shed light on both formal and informal rules and practices of governance transfer by ROs.

Third, the data set provides for a systematic assessment of trends across regions, and across standards. While many studies of ROs rely on single-case studies or comparative case studies (e.g. Hawkins and Shaw 2008; Legler and Tieku 2010), we make use of a systematic comparison of 12 ROs located in different parts of the world. We cover a wide range of Western and non-Western ROs that significantly differ with regard to their institutional design and member states. We also look at both continental and subregional organizations. Continental ROs, such as the Council of Europe (CoE) and the African Union (AU), cover almost all of the states in a particular macro-region and tend to deal with political and cultural matters. Subregional ROs, such as the Southern African Development Community (SADC) and the Association of Southeast Asian Nations (ASEAN), are exclusive to states from a subregion and often focus on economic integration. This approach enables us to detect similarities and differences between and across governance standards and instruments, and those macro-regions that have not been systematically examined thus far.

\section{The emergence and evolution of governance transfer}


The focus of this empirical section lies on mapping the timing, increasing precision, and broadening scope in the prescription of both standards for legitimate governance institutions and the instruments for their promotion and/or protection. We start by providing a general overview of the evolution of governance transfer standards since the foundation of 12 ROs in the postWorld War II and post-Cold War era, and discuss the timing of prescription and intensities of prescription rates over time. Overall, our analysis identifies a trend towards the general prescription and increasing precision of governance standards. Following a first round of adoptions in the early 1950s, ROs rarely prescribed governance standards in the following decades. The process then picked up speed in the 1990s until the number of prescriptions culminated around the turn of the millennium. However, the prescription of governance standards did not necessarily go hand in hand with their more precise elaboration, and often subsequent legislation led to increasing precision. As for the instruments, the results are more mixed and vary across issue areas. Instruments for promoting human rights, democracy, and the rule of law were available and precise in some ROs. The prescription of instruments intensified when ROs increased the precision of governance standards. While we find similar types of instruments in both the human rights and anti-corruption regimes, instruments vary for the democracy and rule of law standards across regions.

We then discuss the broadening scope of governance standards and instruments in more detail. We find that both vary across time, across macro-regions, and across standards. The broadening of scope of governance transfer seems to be decentralized and fragmented. ROs from Africa, the Americas, and Europe place different weight on particular standards and apply significantly different instruments from each other. We also identify outliers regarding the timing of prescription and the scope of governance transfer.

\section{Timing and intensity of prescribing governance transfer}

The analysis of the evolution of governance transfer substantiates our assumption that there is a global trend in prescribing governance transfer by ROs from 1948 to 2012. At the same time, this is not a uniform process, as the timing and intensity of prescription vary. We find that there is a consistent group of continental ROs which set the pace in prescribing governance standards and 
instruments. These pioneers are followed by the subregional organizations, notwithstanding some organizations withholding from prescribing particular standards until the very end of the period under study.

\section{The prescription of standards}

While there seems to be a global trend towards ROs prescribing standards for legitimate governance institutions, there is no clear-cut breaking point. Figure 2.1 displays the prescription of each of the four abstract standards that we cover in this chapter. For all four standards, the prescription rates represent S-curves (Rogers 2003). Once a standard was prescribed by a single or a few ROs, it took a considerable amount of time for other ROs to follow suit. A steep increase in the prescription of the four standards occurred in the late 1990s and early 2000s, where we see a clustering and the highest intensity of prescription overall. At the end of this period, almost all ROs acknowledged the four standards in their efforts at governance transfer in their member states. Ten out of 12 ROs adopted anti-corruption norms, while 11 out of 12 ROs covered the other three standards. There lies, of course, quite a long period of time between the initial reference to democracy, human rights, and rule of law in the 1950s and 1960s, and the increasing prescription rate of these norms around the turn of the millennium. This trend is not driven by the foundation of additional ROs. The Commonwealth of Independent States (CIS) and North American Free Trade Agreement (NAFTA) already prescribed governance standards in 1991 and 1993, respectively, and thereby do not account for the steep slope of the lines shown. Mercosur is the only newly established RO (1994) that contributes to the increasing prescription rate around the turn of the millennium. Excluding the newly established ROs would, therefore, not change the displayed curves. Furthermore, we have cursorily cross-checked these developments with other ROs and found similar results.

[About here Figure 2.1 Timing and intensity of prescribing governance standards]

However, the prescription of governance standards by ROs is not a uniform process. The evolution of the prescription of the four broad standards varies significantly in timing and intensity. The number of prescriptions for human rights in ROs increases steadily over time. We find a different timing and intensity for the other three standards. The prescription rates of the 
democracy and rule of law norms represent flat S-curves, meaning that after their emergence early on in the 1950s only a handful of ROs followed the example of the pioneering organizations over the next decades. The number of ROs that prescribed standards in the fields of democracy and rule of law then doubled from five to 11 around the turn of the millennium. This period of high intensity leveled off after this point, also because of the limited number of ROs covered in our data. On the contrary, the S-curve for the adoption of anti-corruption norms is slightly steeper than for the other three standards. Initially, anti-corruption lagged behind in its evolutionary process compared with the other abstract standards. First formally mentioned by the $\mathrm{CoE}$ in the Convention on Laundering, Search, Seizure and Confiscation of the Proceeds from Crime in 1990, the fight against corruption was addressed in a single-purpose treaty to the issue and hence formalized by the Organization of American States (OAS) in 1996 (see Lohaus forthcoming). The number of ROs prescribing standards promoting the fight against corruption quadrupled from 1998 to 2004. At the end of this time period, the number of ROs that set anticorruption norms almost equals the number of prescribers of the other governance standards.

Governance standards emerged first in the continental ROs. The OAS and the CoE already prescribed human rights standards at the dawn of their establishment in 1948 and 1949, respectively, and the Organization of African Unity (OAU) did so in 1963. The same holds true in the case of the democracy standard for the $\mathrm{CoE}$ and the OAS. In addition to this, the $\mathrm{CoE}$ started to promote the rule of law in 1949, while the OAS followed suit in 1969, as did the OAU, but not until 1981. Although anti-corruption only emerged later on, again the OAS and the CoE, as continental ROs, moved first. The subregional organizations prescribed these standards on a varying basis. In some instances, African ROs set standards sooner than their Latin American counterparts. In other instances, it was the other way around. The only real outlier is NAFTA, which does not prescribe any explicit standards. While some particular governance standards might be present in NAFTA, one has to acknowledge that NAFTA is an organization that mainly supervises the implementation of an almost complete contract (see Duina forthcoming). This makes a renegotiation or amendment of the agreement rather unlikely after the original establishment. It is hence not surprising that NAFTA has not adopted any of the four areas' abstract standards. Meanwhile, NAFTA and Mercosur are the only ROs in our data set that have not prescribed any provisions for the fight against corruption. Yet, Mercosur member states at least acknowledge the problem and reiterate their commitment to harmonizing domestic anti- 
corruption legislation by directly referring to the Inter-American and UN Conventions in official statements.

\section{The provision of instruments}

With regard to the mechanisms to induce compliance, the prescription of standards was not necessarily linked to the provision of instruments for their active promotion and/or protection. Some ROs left it at the mere prescription of standards for legitimate governance in their member states. Overall, regional dialogue was the most common instrument that was used in governance transfer approaches. While harder types of instruments, such as military intervention and sanctions, feature far less frequently, there is significant variation with regard to the timing of their creation across both the macro-regions and the respective standards.

Continental ROs were not only first-movers in prescribing human rights; they also linked the standards to instruments for their promotion and/or protection. All continental ROs introduced monitoring instruments. These are mainly commissions on human rights, which even the League of Arab States (LAS) had early on (van Hüllen forthcoming). The CoE foresaw the European Court of Human Rights in the European Convention on Human Rights, and the court became operational in 1959. The OAS and the AU, by contrast, only added this instrument in 1969 and 2008, respectively. A human rights court is still under consideration in the LAS. Moreover, subregional organizations came late in providing instruments for human rights protection and promotion. Due to reasons of overlapping membership, they were supposed to operate within the continental human rights regimes, for instance, of the OAS, the AU, or the CoE. Since the AU human rights regime lacked judicial enforcement, however, the SADC Tribunal and the Economic Community of West African States (ECOWAS) Community Court of Justice have actively sought to protect human rights within their jurisdiction. By now, human rights courts are available or are in the process of being made available in almost all macroregions. The exceptions are NAFTA and SADC, the latter of which abolished its tribunal after it had assumed human rights jurisdiction on issues of land reform (Hulse and van der Vleuten forthcoming). 
The provision of instruments is less uniform with regard to the three other standards, with instruments being prescribed only later. The creation of most of the instruments coincides with the highest intensity of elaborating the precision and scope of governance standards (see below). Until the turn of the millennium, dialogue was the main instrument available to ROs to induce compliance with democracy standards. Ever since then, election assistance has been added for promoting democracy in the member states. It aimed at both institution- and capacity-building, for instance by devising independent national electoral authorities. The more common instrument adopted by almost all ROs was, however, election observation missions sent to monitor the free and fair conduct of elections (Kelley 2012). Election monitoring was increasingly organized and provided for by the $\mathrm{RO}$, although these assistance missions were often dominated by particular member states. Even ASEAN and the LAS, which have been reluctant to promote democratic governance, prescribed their own election-monitoring missions (cf. Donno 2010).

We also find instruments to promote and/or protect the rule of law in the African, American, and European cases. Some ROs made use of incentive and sanction mechanisms early on, for example when they introduced the possibility of suspending membership or certain membership rights for a limited period of time (McMahon and Baker 2006). Again, the CoE and the OAS were at the front line of this development. Subregional organizations caught up with these instruments, and sometimes even prescribed harder instruments with regard to the rule of law. In addition to the suspension of membership, in 1999, ECOWAS introduced the right to militarily intervene in the domestic affairs of its member states - even against the will of the member state concerned. This is the most far-reaching instrument we have been able to find in our comparison across ROs (Hartmann and Striebinger forthcoming). The other African ROs followed suit as SADC and the AU adopted similar mechanisms of military coercion in the early 2000s. These rule of law standards can be democratically loaded. Instruments then only apply in the context of rule of law violations accompanied by a negative impact on the democratic or human rights situation of the member state (Leininger forthcoming). Lastly, we do not find many instruments to promote particular norms for the fight against corruption. If at all, ROs rely on dialogue and some kind of regional monitoring instruments and follow-up mechanisms.

The analysis of governance transfer documents also reveals that some ROs provide only very soft, if any, instruments to induce compliance. As we have mentioned above, some ROs 
have refrained from introducing instruments because another one was already available to the member states due to their overlapping membership in subregional and continental ROs. Although this might be intentional, it is all the more striking when some ROs that were active in the prescription of governance standards do not make instruments available at all. Once again, the LAS and ASEAN were the outliers and do not provide any particular instrument to promote the rule of law in their member states. Finally, NAFTA itself does not prescribe many standards in need of promotion in the first place.

\section{Increasing precision of governance transfer}

\section{The precision of standards}

In the operationalization of governance transfer, we have put forward a more nuanced understanding of the rather abstract standards of democracy, human rights, rule of law, and the fight against corruption. This operationalization allows us to examine the prescription of more specific norms over time. Results indicate that the introduction of standards of legitimate governance institutions did not necessarily go hand in hand with the precision of its content. In some cases, precision deviates significantly from the initial prescription of standards. Alternatively, ROs started by putting forward more precise norms without setting any abstract standards or subsuming them under the abstract standards.

While ROs initially showed their commitment to the promotion of legitimate governance institutions in their member states, an elaboration of what they actually meant by these commitments often only followed several years later. Two examples nicely illustrate this pattern. The CoE had already introduced a democracy clause in 1949. It only fleshed out this clause in the mid-1990s when the member states further specified certain sets of rules and procedures regarding the dimensions of representation, participation, and elections (Gawrich forthcoming). When the OAU acknowledged the necessity of adhering to human rights in its member states, it referred to fundamental political and civil rights, and cultural and collective rights, first. Only in 1981 did the OAU add provisions for social and economic rights and cross-cutting issues. Likewise, we find many examples that could illustrate the robust finding of longer periods of 
time stretching between the initial prescription of standards and their subsequently increasing precision.

We have to acknowledge that standards evolve over time and are not necessarily available in full specification at the time of their prescription. However, when comparing instances of subsequently increasing precision, we see that other ROs had more precise concepts at the same time as the ROs initially introduced the standards mentioned above. The OAS had already developed specific norms for democracy promotion at the time when the CoE prescribed only the broad standard. Similarly, when the OAU and ASEAN introduced human rights and rule of law standards, respectively, both the OAS and the CoE had precise human rights and rule of law norms covering all dimensions that have been coded in our data set. This claim holds true for other instances, especially around the turn of the millennium when governance standards were widely available and accessible.

A second finding from the more nuanced analysis of governance standards reveals that some ROs put forward precise norms while not conceiving them under the four broad standards that we identify as major points of reference. Although the subsequent generalization of norms into broad standards was far less frequent, we find it for several ROs. The European Union (EU) mentioned the famous principle of 'equal pay for equal work' in article 119 of the Treaty of Rome in 1957. The equal remuneration for women and men is a cross-cutting gender right that is present as a norm in most ROs by now, but other ROs introduced the more abstract human rights standard first. Other ROs showed similar developments when precise norms preceded general standards, such as the right to free movement in the ECOWAS Protocol Relating to Free Movement of Persons, Residence and Establishment in 1979, and social and economic rights in the Declaration of ASEAN Concord in 1976.

\section{The precision of instruments}

As we mentioned above, many ROs provided instruments when they first prescribed governance standards. In those instances, the instruments were already quite precise. If ROs mentioned dialogue, assistance, incentive, or litigation, they also further elaborated the conditions under which these instruments would apply and which decision-making processes were to be used. 
Hence, while we find an elaboration of more precise standards over time, this process was often only accompanied by the prescription of new and different, rather than more precise, instruments.

We found only mixed evidence regarding the increasing precision of instruments. Increasing precision occurred occasionally and did not systematically increase over time. This does not mean that the instruments have not changed. The European human rights instrument is a case in point. The European human rights regime was fairly precise at the time of prescribing standards and instruments. The CoE redesigned the European Court of Human Rights to a fulltime institution in 1998 and abolished the European Commission of Human Rights, which previously decided upon the admission of applications. Although the CoE changed the setup of its human rights instruments over time, this was not about greater precision.

\section{Broadening scope of governance transfer}

Only looking at the prescription of governance standards does not tell us much about what has been prescribed by ROs, and whether similarities and differences exist. The list simply does not provide information on the dimensions, norms, and instruments covered by each RO. To shed more light on the scope of governance transfer, we will now discuss the developments and characteristics of governance standards and instruments as exemplified by variations across regions and across abstract standards. While the scope of instruments in the anti-corruption regime has not changed over time, we find a broadening scope of instruments for the democracy and rule of law standards in all ROs and for human rights standards in some ROs. However, the scope of governance standards and instruments again varies across regions.

\section{The scope of standards}

The radar charts in Figure 2.2 represent the average presence of prescribed standards for human rights, democracy, rule of law, and fight against corruption. These radar charts are based on unweighted mean values of the number of coded standards broken down to the main dimensions as developed in the operationalization of governance standards. This allows us to discuss developments across standards without getting lost in a too detailed review and comparison of 
very precise standards. For instance, the fundamental political and civil rights dimension is composed of 27 individual precise standards. When nine of these standards are present at one point in time in an $\mathrm{RO}$, this is depicted as a value of 0.33 under the fundamental political and civil rights dimension in the radar chart. As outlined above, most activities on governance transfer occurred around the turn of the millennium. Figure 2.2, therefore, provides illustrations for the variation in standards for legitimate governance institutions in 1998 and in 2004.

[About here: Figure $\mathbf{2 . 2}$ Scope of governance standards]

Differences in the scope of governance standards become apparent on the global scale. The human rights regime was already very well developed and specified in 1998, but there was a steady increase in ROs which took on a similar set of governance standards up until the year 2004. This is represented in the radar graphs in Figure 2.2 by the expansion of the main dimensions covered under the human rights label, while at the same time the geometric form does not change much. The only exceptions are the social and economic rights, which seem to be slightly more prevalent in ROs by 2004, but this trend diminishes over the following years. By the end of the time period under study, 60 per cent of the items that we covered are present in the three dominant dimensions of human rights (fundamental political and civil rights, social and economic rights, and cross-cutting rights). In absolute terms, ROs prescribed 45 out of 76 standards in these three dimensions, on average.

Compared with the human rights regime, the other three governance standards were only rudimentarily developed at best on a global scale and hardly existent in some macro-regions at the beginning, but then showed an equally increasing broadening of scope over time. However, anti-corruption shows a trajectory similar to the one we found in the case of human rights. The coverage expands while the initial geometric form is preserved. This means that a higher number of ROs prescribed a similar set of governance standards and/or that ROs further broadened the scope but relied on the initial focus. In contrast, both the democracy and the rule of law regimes change their geometric forms over time. In the case of democracy, ROs increasingly set more standards regarding the participation of people in democratic processes, which then outran the initially more widely covered representation and election dimensions. While standards regarding promulgation and justice dominated the rule of law dimension in the beginning, the standards for principles of state organizations and supremacy of law picked up speed and were, in time, just as 
widely covered. Overall, we find that gradually ROs distinguished between the main dimensions of abstract governance standards and set more specific norms. The varying scope across specific norms and the expansion of coverage echo our previous finding on the precision of governance transfer: that ROs committed themselves to abstract standards first but subsequently specified them.

The radar graphs also depict a significant macro-regional variation. ROs in Sub-Saharan Africa were more likely to set standards to promote democratic participation, to protect principles of state organization and the supremacy of law, or to define the concept of corruption. South American and American ROs, in turn, tended to promote economic and social rights as well as cultural and collective rights in the area of human rights, although the latter aspect only took off after 2004 and is not portrayed in Figure 2.2. Standards for promulgation and justice were promoted more often in these ROs than other rule of law dimensions. In Europe, the human rights standards featured very prominently compared with the other three issue areas. European ROs placed more weight on representation and accountability in the democracy issue area, and justice and promulgation in the rule of law issue area. The most substantive change occurred in the fight against corruption between 1998 and 2004, when the scope of two specific norms broadened, namely, the definition of corruption and its prosecution, penalties, and sanctions.

Overall, the consistently similar scope of human rights and fight against corruption on a global scale may be related to the existence of well-defined international regimes. Yet, the macro-regional comparison shows that this is only half of the story. ROs can strikingly deviate from the global averages. We detect more items regarding the definition of corruption in documents issued by ROs from Sub-Saharan Africa than on the global scale: almost 90 per cent of the items in Sub-Saharan Africa compared with about 50 per cent on global average. The LAS covers many more items of the promulgation and justice dimension in rule of law. The democracy dimensions diverge even more in the Sub-Saharan African ROs after 2004 as the AU, ECOWAS, and SADC issue several documents related to elections and standards of democratic governance. ROs further develop governance standards. Similar scopes of governance standards seem to be restricted to macro-regions at best, although all ROs emphasize certain governance standards and dimensions. The development of the scope of governance standards, hence, seems to be decentralized and fragmented. 
NAFTA, ASEAN and the Arab League appear to be outliers with regard to the scope of governance standards, but for varying reasons. Again, NAFTA is an organization that mainly supervises the implementation of an almost complete contract. It adopted very few governance standards in its agreements, which have not changed since (Duina forthcoming). The scope of NAFTA's governance standards is already covered in the Americas radar chart in Figure 2.2. Excluding NAFTA from this graph would not change the geometrical form of the graph, as it has adopted only a very few of the items that we cover in the data set. ASEAN, on the other hand, was essentially a latecomer. The organization had made a first, albeit vague, commitment to human rights in the 1970s. The increased precision and broadening of scope only followed in 2007 and 2012, but these changes are not represented in Figure 2.2. While the timing of prescription is unusual in a global comparison, the scope of standards for legitimate governance institutions does not show distinctive and irregular features by the year 2012. Participation was lagging behind democracy promotion and protection. ASEAN also placed little emphasis on the issue of corruption, and differed from other organizations by not directly requiring member states to change national law. However, ASEAN at least acknowledged the importance of this issue, and anti-corruption agencies from eight member states have signed a memorandum of understanding. The LAS, indeed, followed the trend of the early prescription of governance standards with subsequent elaboration around the turn of the millennium. This is especially apparent in the human rights regime. While the LAS has virtually no standards in place in 1998, despite some shallow human rights commitments, broadening of scope and expansion to other areas of governance transfer followed in 2004 and 2010 (van Hüllen forthcoming). However, the organization's approach to governance transfer varied from other macro-regions in terms of scope. The LAS outperformed the other ROs and adopted many more specific norms, with a focus on the promulgation and justice dimension. Democracy, by contrast, was underdeveloped compared with the other standards in the LAS and compared with the other regions, whereas anti-corruption followed the global trend. NAFTA, ASEAN, and the Arab League all present outlier cases in the macro-regional comparison. The setup of NAFTA does not allow for change over time. ASEAN is late in adopting standards similar to the global average. Not only is the LAS late, but the scope of its different standards also shows a unique pattern. 


\section{The scope of instruments}

While ROs introduced instruments simultaneously with the prescription of abstract standards, they frequently changed old and added new instruments as part of the increasing precision and the broadening scope of governance standards. They thereby broadened the scope of instruments overall for the human rights, democracy, and rule of law standards. Next to the almost omnipresent dialogue instrument, ROs provided a multitude of additional instruments. The anticorruption standard, however, was initially characterized by a comparatively broad scope of instruments, which was not further broadened over time.

The instruments to promote human rights are broad from the beginning, ranging from dialogue to monitoring and from sanctions to litigation. Especially the $\mathrm{CoE}$ and the OAS provided for a comprehensive setup of regional human rights commissions and courts early on. Most of the subregional organizations increasingly adopted the instrument of litigation and, hence, showed some trajectory to a broader scope of instruments. Since the CoE, the OAS, and the AU prescribed independent human rights courts, most countries in the world can be scrutinized by this instrument. Only the member states of ASEAN and the LAS are not subject to a regional human rights court, but these ROs at least have human rights commissions that are supposed to monitor human rights situations and violations. The more interesting comparison relates to the scope of the respective instruments. Looking at human rights courts, variation occurs regarding matters of individual access to the regional system of adjudication and the appeal of verdicts by national courts (cf. Alter 2014). Overall, the scope of instruments broadens with regard to the promotion of human rights both across types of instruments and within types of instruments.

A significant change in the scope of instruments became apparent with regard to the democracy and rule of law standards. ROs merely prescribed democracy standards but did not establish instruments for their promotion. The limited to non-existent scope of instruments changed in the early 1990s, when most ROs started to develop instruments, focusing on dialogue and assistance. As we have mentioned above, ROs mainly refer to election assistance and election monitoring. In addition, they also prescribed the possibility of suspending membership rights and/or membership in general, although ASEAN and the LAS have not followed this trend. In cases of unconstitutional changes of democratic government or of (massive) human 
rights violations, some Sub-Saharan African ROs even preview the use of military force. Again, this was the hardest instrument we were able to detect in all ROs (Hartmann and Striebinger forthcoming). Overall, we find an increasing scope over time across the various types of instruments to promote democracy and rule of law, but with some significant variation across regions.

In the promotion of the rule of law, even more variation can be detected. ROs increasingly prescribed a broadening scope of instruments and harder types of instrument, especially in the dimensions of both principles of state organization and supremacy of law. For this 'formal' perspective of rule of law, which defines procedural requirements of the legal framework, ROs have increasingly sought to use instruments that range from dialogue to sanctions. The first prescription of rule of law standards issued by the CoE was supported by a sanctioning mechanism, as membership rights could be temporarily suspended. As we have mentioned above, these rule of law standards can be democratically loaded. On the contrary, when it comes to the second 'substantial' approach of the rule of law standard, ROs did not establish instruments going beyond regional dialogue, if they prescribed any instrument at all.

In the fight against corruption, the scope of instruments ranged from dialogue to assistance to monitoring, but was rather similar across the regions. Comparatively harder instruments, such as negative sanctions and independent regional litigation, were not part of the portfolio of instruments. While this reflected a rather broad scope of instruments in the beginning, we do not find any trend reflecting a broadening scope of instruments. After almost all ROs prescribed standards in the fight against corruption, these protocols and legislation were rarely subject to amendment or revision. The 2001 Report of Buenos Aires on the Mechanism for Follow-up on Implementation of the Inter-American Convention against Corruption was the exception that proved the rule. The scope of instruments in the fight against corruption represents a mix of different instruments.

All in all, the scope of instruments that have been provided for the active promotion and protection of governance standards is broadening over time. Especially around the turn of the millennium, ROs have developed a mix of instruments ranging from soft to hard instruments despite variation across the regions and across the governance standards. The hard types of 
instruments - sanctions and litigation - can especially be found for the promotion and protection of democracy and human rights standards in the American (except for NAFTA), European, and Sub-Saharan African cases. ECOWAS and SADC even introduced military interventions in the case of massive violations of human rights, democracy, or rule of law standards. A number of soft instruments complement their approaches. This results in a broad mix of instruments for the promotion of democracy and human rights in these ROs. While soft instruments are available in all dimensions of governance standards, the promotion of rule of law and anti-corruption standards tend to be exclusively promoted through dialogue and assistance (although some dimensions of the rule of law sometimes come with harder instruments, as exemplified by suspension clauses in the CoE and the OAS). Finally, ROs from the Americas, Europe, and SubSaharan Africa have a multitude of instruments at their disposal, both soft and hard. On the contrary, ASEAN and the LAS exclusively rely on soft instruments directed at regional dialogue and capacity-building, and NAFTA does not provide any instruments for the active promotion and/or protection of governance standards.

\section{Conclusion}

Our findings suggest that governance transfer by ROs may indeed follow a global trend. ROs around the globe increasingly prescribe governance standards on human rights, democracy, rule of law, and the fight against corruption. Even predominantly non-democratic ROs, such as the LAS, the CIS, or ASEAN, at least make reference to these abstract standards for the governance institutions of their member states. The initial prescription of governance standards tends to be followed by a large number of secondary legislations leading to the elaboration of abstract norms into more precise norms and, further, to the broadening of scope of both content and instruments over time.

However, these processes are not uniform. Rather, we see significant variation between regions and among the four standards. While ROs from Sub-Saharan Africa are strong proponents of rule of law norms and participation rights as part of their democracy standard, American ROs, such as Mercosur and Community of Andean Nations (CAN), have focused on cultural and collective human rights. The OAS and the CoE are among the early adopters of standards promoting the fight against corruption. Given these regional variations, it seems 
unlikely that ROs simply download a central governance script or pick and choose from a global menu. This might hold true for human rights, where we find a strong and widely recognized international regime and the United Nations (UN) as a capable promoter of these norms. Likewise, but less so, the development of a global anti-corruption script has gathered speed ever since its emergence in the early 1990s, with the OECD and the UN forming the core of an emerging global regime. Democracy and rule of law, by contrast, so far lack a central institutionalization of norms.

The provision of instruments to promote and protect governance standards also significantly varies between regions and among the four standards. Most of the instruments are developed when ROs increase the precision and broaden the scope of governance standards. We find a mix of hard and soft instruments, ranging from dialogue to sanctions, in the American, European, and Sub-Saharan African ROs and for the human rights and democracy standards. Note, the right to militarily intervene in order to protect governance standards is exclusively available in Sub-Saharan Africa, which suffers from serious problems of regional instability. On the contrary, soft instruments prevail in ASEAN and the LAS, which have emphasized the primacy of non-interference, as well as in the more recent regional anti-corruption regimes. Over time, the scope of instruments broadens as more types of instruments are institutionalized and are supposed to complement each other.

Overall, we do not find patterns of convergence or increasing similarities for the four governance standards and their instruments. Regional variation is most visible in the standards for democracy and the rule of law. When adding the instruments to ensure compliance with governance standards to the picture, there is even less evidence for convergence over time and across regions.

At the time of the first prescription of abstract standards for legitimate governance institutions, ROs follow the global trend, which might indicate the diffusion of a global script. Precision and scope of governance transfer and the development of instruments, however, seem to be driven by functional and normative demands internal to the region. In other words, there is no complete decoupling of the formal commitment to abstract governance standards at the regional level from their application and enforcement in the member states, as world society 
theory would expect (Meyer et al. 1997). Without making any claims about the effectiveness of governance transfer by ROs, we do observe the development of a set of instruments to promote the prescribed standards on the ground.

The differences in precision and scope of governance transfer could, nevertheless, still be regarded as part of a global diffusion process in which the global script becomes 'localized' (Acharya 2004). When the commitment to abstract standards is no longer sufficient to satisfy the particular demands of ROs, such as international legitimacy and curbing negative externalities, ROs may increase the precision and broaden the scope of standards and introduce harder instruments in order to (re-)establish compliance at the member state level (Risse et al. 2013). The increasing precision of governance standards is then already a step towards more and better compliance, because rules have to be sufficiently clear and available to be followed by the addressee. If an increase in precision is then followed by reform or setup of harder instruments, ROs have done much of what they can do in order to promote and/or protect legitimate governance institutions. These instruments, however, still need to be activated by the respective authorities and institutional bodies at the domestic level and subsequently enacted.

ROs may selectively read from a global script and translate parts into their local context in accordance with their specific functional and normative demands (Börzel and van Hüllen forthcoming). Further research will explore to what extent this process of "co-authoring the script' is fueled by processes at the global level or else unfolds in a decentralized and fragmented fashion. When ROs introduce standards for legitimate governance institutions or further substantiate these standards, others tend to follow their example. These processes can be driven by various factors, ranging from competition concerns and learning effects to pure mimicry (inter alia Simmons et al. 2008; Börzel 2012b).

\section{Notes}

1 These 12 ROs are the AU, ECOWAS, SADC, ASEAN, the LAS, CIS, the OAS, NAFTA, Mercosur, CAN, the CoE, and the EU.

2 It is beyond the scope of this paper to present all the items, norms, and rules which could be present in treaties and which have been coded in the data collection process, so please refer to the codebook for more detailed information on the respective dimensions (Stapel forthcoming). 


\section{References}

Acharya, A. (2004) 'How Norms Spread: Whose Norms Matter? Norm Localization and Institutional Change in Asian Regionalism', International Organization 58(2), 239-275.

Alter, K. J. (2014) 'Contemporary International Adjudicators: Evolution and Multiplication', in C. Romano, K. J. Alter, and Y. Shany (eds), Oxford Handbook on International Adjudicatiation (Oxford: Oxford University Press), 63-89.

Alter, K. J. and L. Hooghe (forthcoming 2015) 'Dispute Settlement Systems', in T. Börzel and T. Risse (eds.), The Oxford Handbook of Comparative Regionalism (Oxford: Oxford University Press).

Börzel, T. A. and T. Risse (2009b) 'Venus Approaching Mars? The European Union's Approaches to Democracy Promotion in Comparative Perspective', in A. Magen, M. McFaul and T. Risse (eds.), Democracy Promotion in the US and the EU Compared (Houndmills: Palgrave Macmillan), 34-60.

Börzel, T. A. and T. Risse (2012b) 'When Europeanization Meets Diffusion. Exploring New Territory', West European Politics 35(1), 192-207.

Börzel, T. A., V. van Hüllen and M. Lohaus (2013) 'Governance Transfer by Regional Organizations. Following a Global Script?' SFB(-Governance Working Paper Series, No. 42, Collaborative Research Centre (SFB) 700, Berlin.

Börzel, T. A., V. van Hüllen, C. Breschke, M. Lohaus and K. Striebinger (2011) 'Governance Transfer by Regional Organizations. Research Guide for Case Study Authors', available at: www.sfbgovernance.de/teilprojekte/projekte_phase_2/projektbereich_b/b2/projektbeschreibung/B 2_Analytical_Framework.pdf

Börzel, T.A. and van Hüllen, V. (forthcoming 2015) Towards a Global Script? Governance Transfer by Regional Organizations, in T. A. Börzel and V. van Hüllen (eds.) Governance Transfer by Regional Organizations. Patching Together a Global Script (Houndmills: Palgrave Macmillan).

Brooks, R. E. (2003) 'The New Imperialism: Violence, Norms, and the "Rule of Law", Michigan Law Review 101, 2275-2340.

de Sousa, L., P. Larmour and B. Hindess (eds.) (2008) Governments, NGOs and AntiCorruption. The New Integrity Warriors (Oxon: Routledge).

Donno, D. (2010) 'Who Is Punished? Regional Intergovernmental Organizations and the Enforcement of Democratic Norms', International Organization 64(4), 593-625.

Duina, F. (forthcoming 2015) Beyond Free Trade: Accounting for Labour and Environmental Governance Standards in NAFTA, in T. A. Börzel and V. van Hüllen (eds.) Governance Transfer by Regional Organizations. Patching Together a Global Script (Houndmills: Palgrave Macmillan).

Forsythe, D. P. (2012) Human Rights in International Relations (Cambridge: Cambridge University Press). 
Gardiner, John (2001) 'Defining Corruption', in A. J. Heidenheimer and M. Johnston (eds.), Political Corruption: Concepts and Contexts (New Brunswick: Transaction Publishers), $25-40$.

Gawrich, A. (forthcoming 2015) Too Little, Too Late? Governance Transfer and the Eastern Enlargement of the Council of Europe, in T. A. Börzel and V. van Hüllen (eds.) Governance Transfer by Regional Organizations. Patching Together a Global Script (Houndmills: Palgrave Macmillan).

Hartmann, C. and Striebinger, K. (forthcoming 2015) Writing the Script? ECOWAS' Military Intervention Mechanism, in T. A. Börzel and V. van Hüllen (eds.) Governance Transfer by Regional Organizations. Patching Together a Global Script (Houndmills: Palgrave Macmillan).

Hawkins, D. and C. Shaw (2008) 'Legalising Norms of Democracy in the Americas', Review of International Studies (34)3, 459-480.

Hulse, M. and van der Vleuten, A. (forthcoming 2015) 5 Agent Run Amuck: The SADC Tribunal and Governance Transfer Rollback, in T. A. Börzel and V. van Hüllen (eds.) Governance Transfer by Regional Organizations. Patching Together a Global Script (Houndmills: Palgrave Macmillan).

Jakobi, A. P. (2013a) Common Goods and Evils? The Formation of Global Crime Governance (Oxford: Oxford University Press).

Kelley, J. G. (2012) Monitoring Democracy: When International Election Observation Works, and Why It Often Fails (Princeton: Princeton University Press).

Landman, T. (2013) Human Rights and Democracy: The Precarious Triumph of Ideals (London: Bloomsbury).

Legler, T. and T. K. Tieku (2010) 'What difference can a path make? Regional democracy promotion regimes in the Americas and Africa', Democratization, 17(3), 465-491.

Leininger, J. (forthcoming 2015) Against All Odds: Strong Democratic Norms in the African Union, in T. A. Börzel and V. van Hüllen (eds.) Governance Transfer by Regional Organizations. Patching Together a Global Script (Houndmills: Palgrave Macmillan).

Lijphart, A. (1995) Electoral Systems and Party Systems. A Study of Twenty-Seven Democracies, 1945-1990 (Oxford: Oxford University Press).

Lohaus, M. (forthcoming 2015) Ahead of the Curve: The OAS as a Pioneer of International Anti-Corruption Efforts, in T. A. Börzel and V. van Hüllen (eds.) Governance Transfer by Regional Organizations. Patching Together a Global Script (Houndmills: Palgrave Macmillan).

McMahon, E. R. and S. H. Baker (2006) Piecing a Democratic Quilt? Regional Organizations and Universal Norms (Bloomfield, CT: Kumarian Press).

Meyer, J. W., J. Boli, T. M. George and F. O. Ramirez (1997) 'World Society and the NationState', American Journal of Sociology 103(1), 144-181. 
Pevehouse, J. (forthcoming 2015) Regional Human Rights And Democracy Governance, in T. A. Börzel and T. Risse (eds.) The Oxford Handbook of Comparative Regionalism (Oxford: Oxford University Press).

Philp, M. (2001) 'Conceptualizing Political Corruption', in A. J. Heidenheimer and M. Johnston (eds.), Political Corruption: Concepts and Contexts (New Brunswick: Transaction Publishers), 41-57.

Przeworski, A., M. E. Alvarez, J. A. Cheibub and F. Limongi (2000) Democracy and Development: Political Institutions and Well-Being in the World, 1950-1990 (Cambridge: Cambridge University Press).

Risse, T., S. Ropp and K. Sikkink (eds.) (2013) The Persistent Power of Human Rights. From Commitment to Compliance (Cambridge: Cambridge University Press).

Rogers, E. M. (2003) Diffusion of Innovations (New York: Free Press).

Rose-Ackermann, Susan (1999) Corruption and Government: Causes, Consequences, and Reform (Cambridge: Cambridge University Press).

Simmons, B. A. (2009) Mobilizing for Human Rights. International Law in Domestic Politics (Cambridge: Cambridge University Press).

Simmons, B. A., F. Dobbin and G. Garrett (eds.) (2008) The Global Diffusion of Markets and Democracy (Cambridge: Cambridge University Press).

Stapel, S. (forthcoming) 'The Governance Transfer Data Set: Concepts and Measurement', SFBGovernance Working Paper (Berlin: Collaborative Research Centre (SFB) 700).

van Hüllen, V. (forthcoming 2015) Just Leave Us Alone: The Arab League and Human Rights, in T. A. Börzel and V. van Hüllen (eds.) Governance Transfer by Regional Organizations. Patching Together a Global Script (Houndmills: Palgrave Macmillan).

Verba, S. (1967) 'Democratic Participation', The ANNALS of the American Academy of Political and Social Science 373, 53-78.

Zürn, M., A. Nollkaemper and R. Peerenboom (eds.) (2012) Rule of Law Dynamics: In an Era of International and Transnational Governance (Cambridge: Cambridge University). 
Figures

Figure 2.1 Timing and intensity of prescribing governance standards

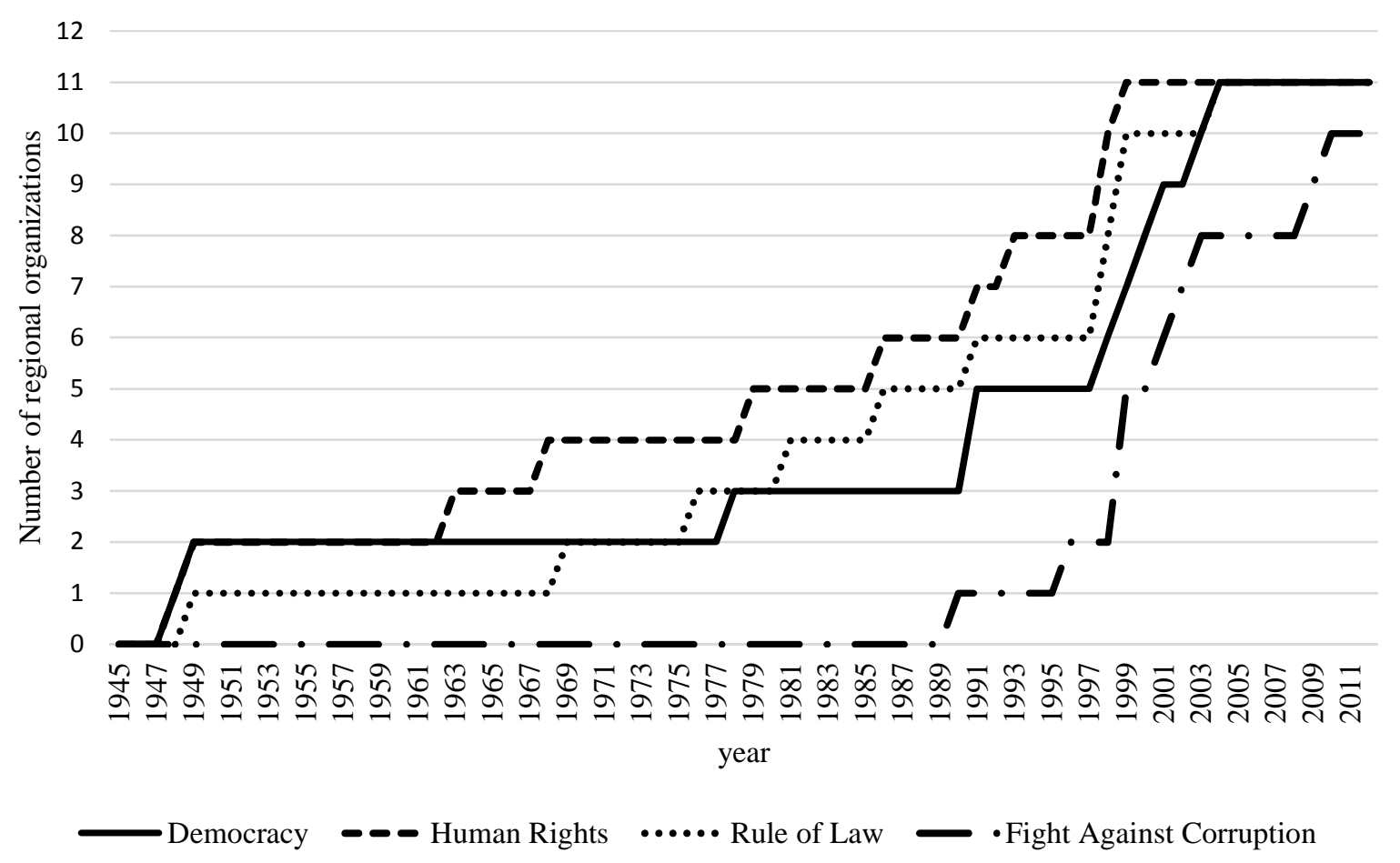


Figure 2.2 Scope of governance standards
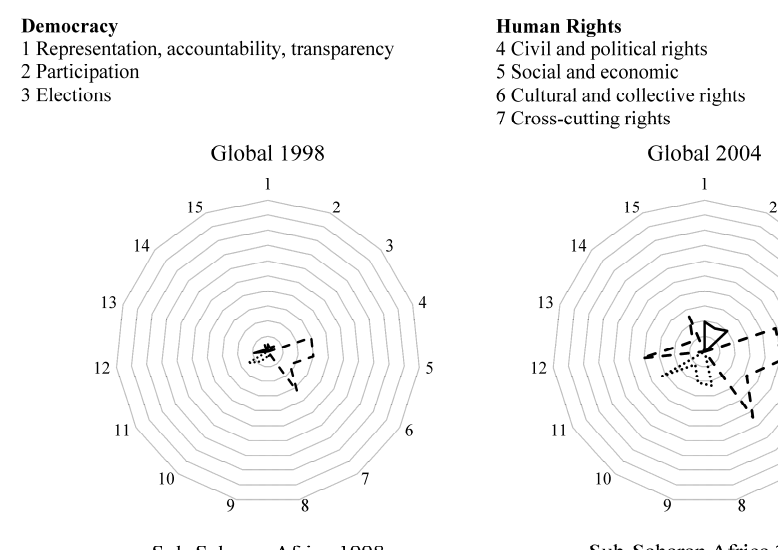

6 Cullural and collective rights
7 Cross-cutting rights
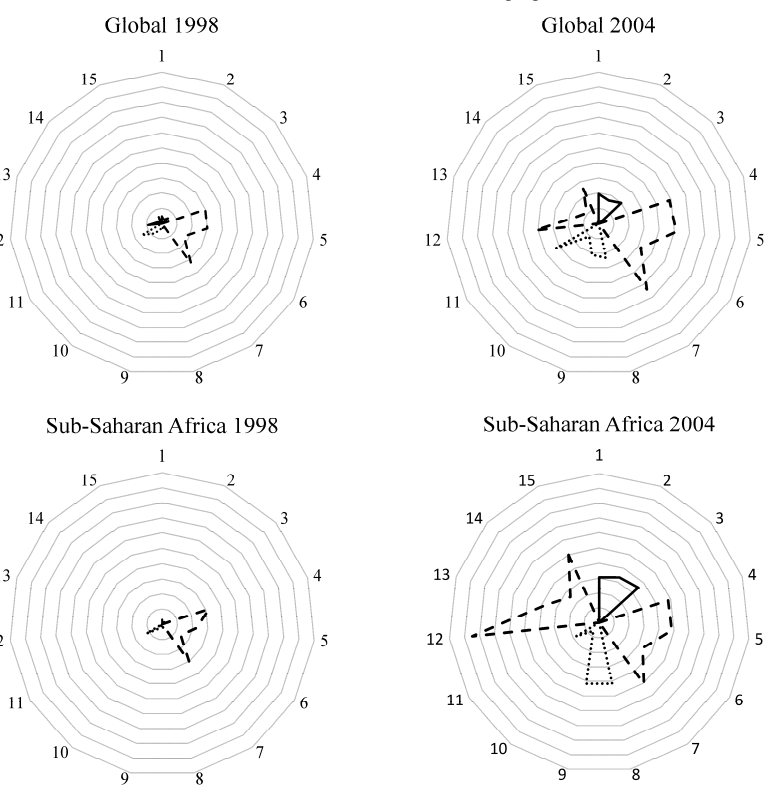

Sub-Saharan Africa 2004

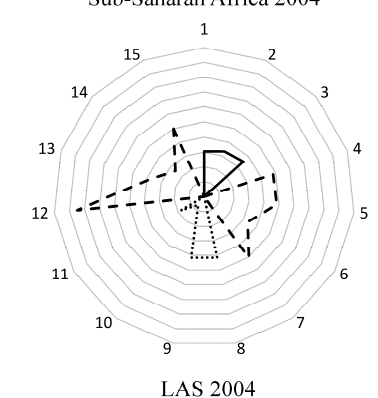

Rule of Law
8 Principles of

12 Definition of corruptio
13 Preventive measures

10 Attributes of law and principles of law-making

Promulgation and justice
ASEAN 1998

14 Monitoring and enforcement
15 Prosecution, penalties, and sanction

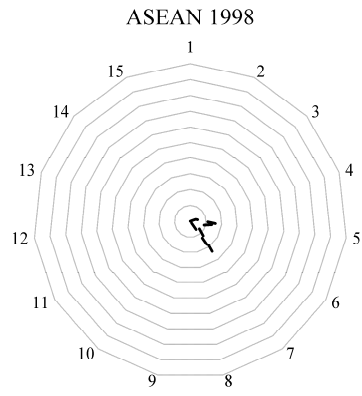
ASEAN 2004
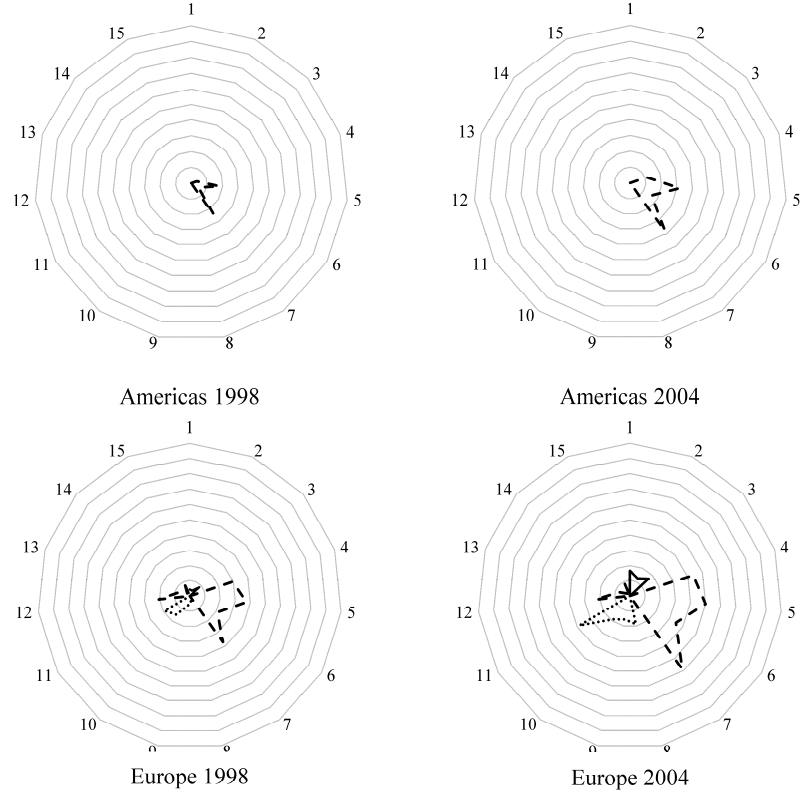

LAS 1998

LAS 2004
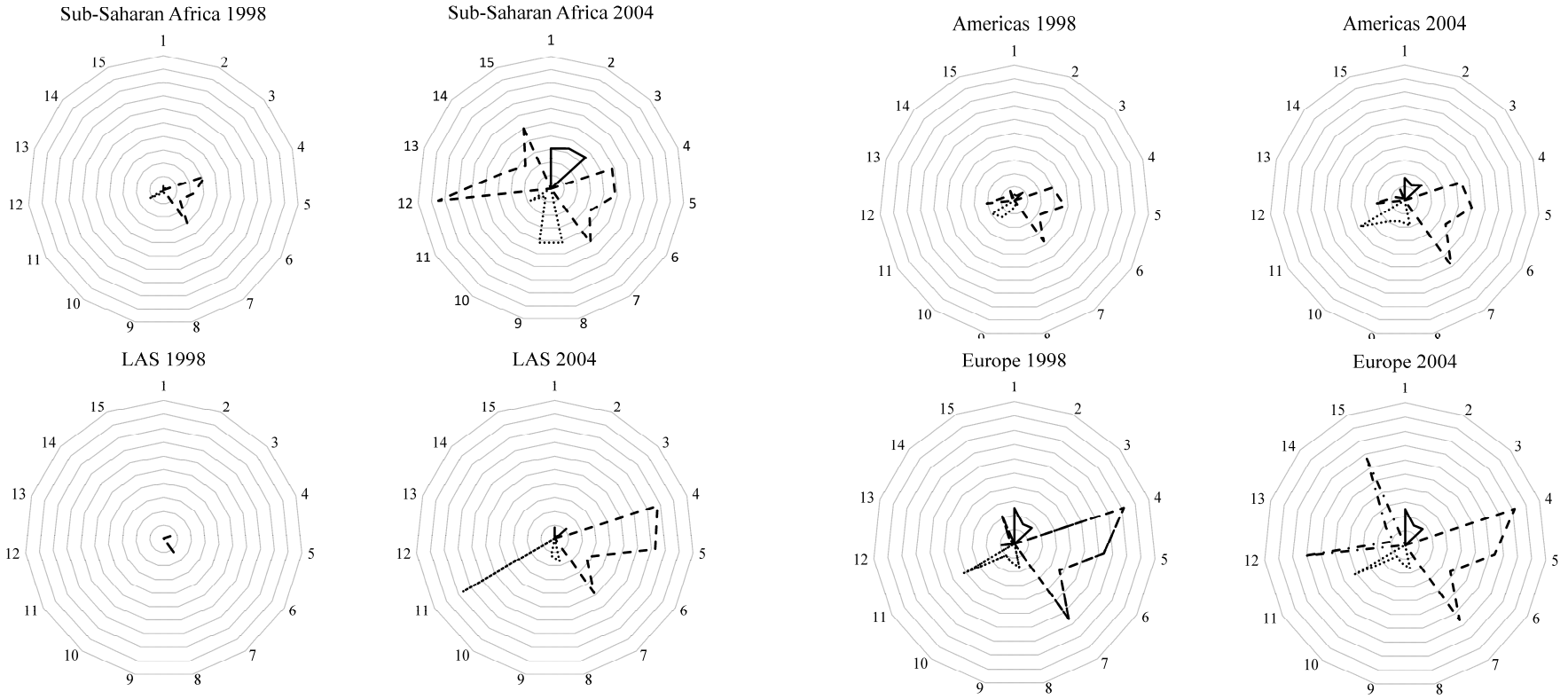